\title{
Lutas sociais pela saúde pública no Brasil frente aos desafios contemporâneos
}

\author{
Marta Alves Santos \\ Associação Brasileira de Ensino Universitário (ABEU-RJ)
}

Lutas sociais pela saúde pública no Brasil frente aos desafios contemporâneos

Resumo: A partir de uma pesquisa bibliográfica e análise documental sobre a temática de estudo, o presente artigo objetiva contribuir para o debate acerca das lutas sociais no âmbito da saúde frente aos desafios postos na atual conjuntura. Analisa a trajetória dos movimentos sociais pela saúde pública brasileira desde 1970 e as formas de resistência e luta diante da ofensiva neoliberal. Aponta os conceitos clássicos e contemporâneos sobre a categoria movimento social, resgata os principais elementos expostos na proposta do movimento sanitário, que deu origem ao Sistema Único de Saúde (SUS), e identifica os desafios para a efetivação de uma saúde pública brasileira em um cenário de restrição do papel do Estado e de fortalecimento do mercado.

Palavras-chave: Movimento social. Saúde. Neoliberalismo.

\section{Social Struggles for Health Care in Brazil in the Face of Contemporary Challenges}

Abstract: Based on bibliographic research and document analysis, the article contributes to the debate about social struggles in the realm of healthcare in the light of current challenges. It analyzes the trajectory of the social movements for Brazilian healthcare since 1970 and the forms of resistance and struggle against the neoliberal offensive. It presents the classic and contemporary concepts about the category of social movement, revives the main elements exposed in the proposal for a public health care movement, which gave origin to Brazil's Single Healthcare System (SUS) and identifies the challenges to implementing a Brazilian healthcare system considering the restricted role of the state and the strengthening of the market.

Keywords: Social movement. Healthcare. Neoliberalism. 


\section{Introdução}

Este artigo analisa as lutas sociais no âmbito da saúde, tendo como referência o movimento sanitário que surgiu em meados dos anos 1970 e o movimento que ganha impulso nos anos 1990, a partir da privatização do Sistema Único de Saúde (SUS). Para tanto, resgata a trajetória histórica da política de saúde no Brasil, como, também, as formas de organização de luta para uma política de saúde mais equitativa.

Nesses termos, torna-se fundamental definir a categoria movimento social, e, através de suas concepções, articulá-la ao movimento da saúde em décadas diferentes. É relevante trazer um recorte sobre a política de saúde brasileira, apontando considerações sobre dois momentos: antes e depois da consolidação do SUS.

O estudo está desenvolvido em três tópicos. O primeiro corresponde à discussão conceitual sobre movimento social, baseada nos paradigmas clássicos e contemporâneos. Nessa dimensão, o segundo tópico traz uma abordagem da política de saúde, resgatando sua história e concepções da década de 1970, com o movimento sanitário. O último item apresenta algumas reflexões sobre a atual conjuntura e sobre o movimento contra a privatização do Sistema Único de Saúde.

\section{Movimento social: conceitos clássicos e contemporâneos}

A gênese da categoria movimento social deu-se em 1840. Identificava o início do movimento dos trabalhadores da Europa e desenvolveu-se no debate do marxismo para representar a organização racional da classe trabalhadora nos sindicatos e partidos que tinham interesse em buscar a transformação socioeconômica das relações capitalistas de produção. Até a década de 1960, a citada categoria fazia referência a qualquer tipo de reação revolucionária do proletariado e dos sindicatos, assim como os partidos políticos comunistas representavam esse tipo de organização (DOIMO, 1995).

No entanto, tal categoria indica uma profunda crise conceitual da temática, pois apresenta uma transmutação de significados e concepções ao longo da história. Com as metamorfoses ocorridas no final da década de 1960, na esfera produtiva, e a crescente institucionalização do conflito de classe nas sociedades capitalistas, ascendem pensamentos que influenciam os parâmetros teóricos e marcam a configuração de outra forma de pensar a categoria como: os novos movimentos sociais. Nas palavras de Doimo (1995, p. 40): "Também a explosão dos movimentos espontâneos que sacudiram a Europa no final dos anos 1960, a desmistificação dos regimes socialistas do Leste e a sucessiva erosão dos esquemas teóricos marxistas acabaram por marcar a configuração de um novo tempo: o tempo dos novos movimentos sociais".

Os novos movimentos sociais rejeitavam as expressões teóricas do liberalismo e do próprio marxismo e trouxeram alguns eixos de debate sobre manifestações da contracultura, sobre as sequelas consequentes do capitalismo avançado, como, também, a crítica ao consumismo e ao individualismo. Tais movimentos eliminam a centralidade de um sujeito específico e os atores sociais são, agora, os participantes de ações coletivas.

Segundo Braz (2012), há um questionamento quanto ao potencial transformador de tais movimentos, pois apresentam uma indefinição quanto aos caminhos possíveis para a transformação social. Essas lutas sociais são percebidas e apresentam seu valor através de experiências vivenciadas e construídas pelos variados grupos sociais que formam os sujeitos coletivos. O autor aponta os pensadores Castells, Lojkine e Touraine como referências no debate sobre os novos movimentos sociais, por suas contribuições acerca da temática.

No Brasil, a categoria movimento social foi referenciada aos movimentos de reivindicações e de lutas urbanas nos anos de 1970, limitados a determinados grupos que pressionavam o Estado a cumprir suas tarefas no campo social. Nesse sentido, o potencial transformador dos novos movimentos sociais seria mais sociocultural do que político.

Braz (2012) afirma que, no caso brasileiro, o debate teórico sobre os novos movimentos sociais divide-se em três fases: a fase conhecida como uma emergência de visão heróica dos movimentos sociais que se situa nos anos de 1970 e início de 1980. Outra, é a marcada pela crítica a uma análise romântica desses movimentos, compreendendo a segunda metade dos anos de 1980. E, por fim, a última fase que se destaca no final dos anos 1980 e início dos anos 1990 e aposta na criação de um espaço de diálogo entre os movimentos sociais com o Estado. Esta propiciou a necessidade de superar as próprias características dos movimentos sociais, cultivadas nas décadas anteriores.

Esses movimentos no Brasil apontavam uma oposição ao Estado, buscavam assegurar a incorporação e a consolidação dos direitos sociais, tornando-se sinônimo de movimentos urbanos. Os chamados novos movimentos sociais apresentam-se como novas formas de participação e sinalizam uma crise do conceito originário da referida categoria.

De acordo com Braz (2012, p. 127), "Esse período teve que enfrentar duas questões de natureza bem distintas, ainda que complementares: por um lado, a exigência de criar uma cultura política de proposição que 
levasse ao exercício da cidadania [...] e, por outro lado, a imperiosa necessidade de preservação da autonomia frente aos riscos da cooptação inerentes ao processo de institucionalização em curso".

As circunstâncias atuais apresentam novos desafios aos movimentos sociais que inscrevem a necessidade de superar características advindas dos próprios movimentos de décadas anteriores, como também, de criar uma cultura política que viabilize ações mais propositivas.

\section{Movimento social pela saúde: movimento sanitário}

Para compreendermos o movimento sanitário no Brasil e sua importância na história da política de saúde brasileira, faz-se necessário resgatar, de forma breve, a trajetória histórica da saúde no país e o contexto que situa cada momento de mudança da referida política. Assim, esse item procura enfocar o início da intervenção do Estado na política de saúde brasileira, nos anos 1920 até os dias atuais.

A política de saúde no Brasil nasce atrelada à política da previdência social, vinculada à Caixa de Aposentadoria e Pensões (CAPs). Na era Vargas (1930-1945), o governo criou o Ministério do Trabalho e elaborou uma vasta legislação trabalhista que enquadrasse a questão social vivenciada no período. Criou, então, os Institutos de Aposentadoria e Pensões (IAPs) organizados por categorias profissionais, garantindo a saúde aos trabalhadores inseridos no mercado formal de trabalho: "Os direitos sociais aparecem aqui de forma particularista, obtidos através da categoria profissional, e da ocupação exercida no âmbito do mercado, sendo a carteira de trabalho o certificado legal da cidadania" (SIMIONATTO, 1997, p. 16).

Os IAPs, que dispunham de recursos financeiros, construíram seus próprios hospitais e introduziam, assim, os primeiros serviços privados contratados por empresas. Caracterizava-se um investimento médicohospitalar em detrimento da atenção básica e, com isso, a consciência dessa questão torna-se visível no período, marcando um impasse na política de saúde.

O governo militar, no período de 1964-1980, realiza a fusão dos IAPs com a criação do Instituto Nacional de Previdência Social (INPS). Esse fato aumentou o poder de regulação do Estado sobre a sociedade. O INPS possibilitou o desenvolvimento do complexo médico-industrial na política de saúde: "A política de saúde no período de 1964 a 1974 desenvolve-se com base no privilegiamento do setor privado, articulada às tendências da política econômica implantada. Suas principais características foram: a extensão da cobertura previdenciária, a ênfase na prática médico-curativa orientada para burocratização do setor, a criação do complexo médico-industrial e a diferenciação do atendimento a clientela" (BRAVO, 2004. p 27).

Nos anos 1970, essa política enfrenta permanentes conflitos entre os interesses antagônicos apontados pelo setor estatal, empresarial e a própria emergência do movimento social da saúde: o movimento sanitário ${ }^{1}$.

O movimento sanitário não aparece isolado do contexto histórico vivenciado nos anos de 1970 no Brasil. Paralelamente, evidencia-se a crise do milagre econômico no país, que permitiu o surgimento no cenário político de alguns atores sociais, como o sindicalismo operário, os trabalhadores rurais, um percentual da Igreja, alinhando-se a certos grupos de trabalhadores, e, também, a outros movimentos sociais urbanos.

A dívida externa, a taxa inflacionária crescente e a recessão econômica possibilitaram desgastes para o sistema econômico e ocasionaram a insatisfação de certos setores da média e da pequena burguesia, o que fortalecia os movimentos sociais emergentes nesse período.

Destaca-se como um dos grandes movimentos sociais da época o da anistia, que buscou fortalecer outras correntes políticas como o movimento feminino de anistia, o próprio movimento da Igreja Católica, organizador das Comunidades Eclesiais de $\mathrm{Base}^{2}$, o movimento estudantil, que se organizava desde 1975, e ainda possibilitou a realização de uma série de passeatas e protestos contra algumas regras do Estado.

Esse cenário de luta e os demais acontecimentos obrigaram o Estado a propor mudanças na política de saúde brasileira como forma de enquadrar a questão social e canalizar as pressões populares. Modificações estas que não deixaram de privilegiar o setor privado e os interesses empresariais. No entanto, foram necessárias que algumas medidas, principalmente de caráter administrativo, fossem regulamentadas nesse período. Temos, em 1974, a criação do Ministério da Previdência e Assistência Social, do Conselho de Desenvolvimento Social e do Fundo de Apoio Social ao Desenvolvimento.

Outras medidas foram tomadas pós-1974, como a criação do Sistema Nacional de Saúde, em 1975. Nesse mesmo período, as Conferências Nacionais de Saúde (CNS) concentravam-se como amplo espaço de debate. Ocorreram, assim, a V CNS, em 1975 e a VI CNS, em 1977, que asseguravam em suas propostas, a participação da comunidade na formulação, fiscalização e implementação da política de saúde.

Cabe salientar que as mudanças realizadas na Política Nacional de Saúde no período de 1974 a 1979 não dispunham da participação da classe trabalhadora. Somente a partir de 1979, ocorre a incorporação de alguns sanitaristas que buscavam fortalecer o setor público de saúde. 
O aumento do custo de vida e a crise econômica com a taxa de inflação a 200\% agravam-se no país, a partir de 1979. Houve, portanto, queda das vendas, da produção e o aumento do desemprego com o arrocho salarial. O período do governo Figueiredo (1979-1985) consolidou o aprofundamento da crise, entre 1980 e 1981, e encaminhou o país a recorrer ao Fundo Monetário Internacional (FMI) em 1982³.

Esse cenário de tensão existente no Brasil desencadeou a consolidação do movimento sindical no período, pois a oposição ao arrocho salarial e as políticas trabalhistas tornaram-se um bandeira de luta para milhares de trabalhadores que consideravam insustentáveis as condições de vida vigentes. O sindicalismo brasileiro entre $1980 \mathrm{e}$ 1984 concentrou sua luta na estabilidade do emprego e nos reajustes salariais de acordo com a inflação da época.

Tem-se ainda, em 1983, o movimento pelas eleições diretas para presidente, que envolveu milhões de trabalhadores brasileiros insatisfeitos com o governo e teve adesão maçica da sociedade ${ }^{4}$.

Esse quadro de tensão também afetava a política de saúde no Brasil, pois as medidas tomadas pelo governo não conseguiam suprir as demandas apontadas, tais como, a unificação do preventivo e curativo e a formulação de uma única Política Nacional de Saúde. Os movimentos sociais questionavam as distorções dessa política, desencadeando a mobilização dos profissionais de saúde em torno de interesses coletivos.

A questão saúde e democracia ganha visibilidade e a relação entre ambas passa a ser apresentada constantemente nas pautas dos movimentos sociais e em suas manifestações. A luta pela saúde ampliou-se e favoreceu a articulação com outras entidades e movimentos populares. Destacavam-se, nesse período, como reivindicações das diversas manifestações: a luta pelo saneamento, água, luz e postos de saúde; a luta pelo fortalecimento do setor público e promoção da saúde e a luta pelas questões concretas da vida, impulsionada pelas Comunidades Eclesiais de Bases.

Esse campo de conflito propiciou o primeiro evento importante na Saúde: a VII Conferência Nacional de Saúde, em 1980, tendo como eixo central "a extensão das ações de saúde através dos serviços básicos", que buscava implementar um Programa Nacional de Serviços Básicos de Saúde e apresentava como pressupostos básicos a extensão da cobertura, a integração dos serviços existentes dos diversos níveis de complexidade e a regionalização do atendimento por área definida, assim como, a participação da comunidade.

Notifica-se, nesse período, uma ampliação do debate em relação à saúde que deixou de ser interesse apenas de um determinado segmento da população para assumir uma dimensão política com vínculos estreitos ao debate da democracia.

A situação econômica no Brasil agravou-se na época de elaboração da constituinte, pois houve o aprofundamento da inflação e precisou novamente recorrer ao Fundo Monetário Internacional. Diante desse quadro econômico, o movimento sindical começa a vivenciar algumas alterações com a diminuição das greves e das taxas de sindicalizados no país. Os movimentos sociais apresentaram tendências de refluxo, caracterizado por uma conjuntura adversa à mobilização.

\section{É nesta realidade de desmonte dos direitos sociais e, consequentemente, do SUS, que se torna necessário resgatar o protagonismo do movimento social pela saúde com a finalidade de superar as propostas impostas pelas agências internacionais do grande capital.} cipais eixos discutidos foram: a saúde como direito de cidadania; a reformulação do Sistema Nacional de Saúde e o financiamento setorial.

A questão da saúde vivenciou avanços e recuos nesse período. Eventos relevantes ocorreram a partir de 1984, como o seminário realizado pelas Secretarias de Saúde dos estados de Minas Gerais, Rio de Janeiro e São Paulo e reuniões de trabalho sobre as Ações Integradas de Saúde, entre outros. Esses eventos possibilitaram o V Simpósio sobre Política Nacional de Saúde, que ocorreu em 1984, e tinha como objetivo apontar propostas e estimular o fomento de vários fóruns de debate sobre a questão da saúde no Brasil.

As Ações Integradas de Saúde (AIS) em desenvolvimento desde 1983 viabilizaram a construção de um novo modelo de atuar e de olhar a saúde, fundamentado na descentralização, na universalização do atendimento e na participação comunitária.

Outro acontecimento considerado um marco histórico no que tange à política de saúde no Brasil foi a consolidação da VIII Conferência Nacional de Saúde, realizada em março de 1986, em Brasília. Contou com a participação de quase 4.500 pessoas, dentre os quais, mil delegados a fim de discutir o rumo da saúde no país. Foi apontada nesse evento a necessidade de reestruturar a política de saúde com a criação do Sistema Único de Saúde. Os prin- 
Após esse importante evento, o governo assumiu a bandeira da reforma sanitária, viabilizou as políticas de Ações Integradas de Saúde e criou o Sistema Unificado e Descentralizado de Saúde em 1987, o SUDS. Em 1988, a Constituição Federal integra a saúde, a previdência e a assistência social ao tripé da Política de Seguridade Social. À saúde coube cinco artigos que juntos constituem um sistema único, pautado pelos princípios de universalidade, equidade, integralidade e da participação da comunidade através do controle social ${ }^{5}$, que resultou na criação do SUS.

No entanto, o SUS foi criado em terreno adverso à sua proposta de universalidade e equidade, pois o projeto econômico neoliberal, consolidado nos anos 1990 no Brasil, confronta-se diretamente com os princípios da reforma sanitária, que é completamente questionada por esse projeto privatista articulado ao mercado.

O projeto privatista da saúde pauta seu discurso na política de ajuste, na contenção dos gastos públicos e na isenção da participação popular na construção de uma política mais democrática. O discurso neoliberal aposta na competitividade e no triunfo do individualismo ${ }^{6}$, cabendo ao Estado garantir o mínimo para atender as comunidades mais vulneráveis.

São condições que desafiam a consolidação do SUS. Segundo Bravo (2004), identifica-se, já na década de 1990, dois projetos em disputa nesta área: o projeto privatista e o projeto da reforma sanitária. O projeto do grande capital defendido por agências internacionais apoia o processo de privatização e a constituição do cidadão consumidor. Contudo, o projeto da reforma sanitária defende os princípios do SUS como a universalidade, a integralidade e a participação social.

O projeto da saúde vinculado ao mercado e à privatização impõe ao Estado a garantia de efetivar apenas ações mínimas na saúde, com caráter focalizado para atender o cidadão que não pode pagar pelo serviço. Essa proposta visa o estímulo à privatização da saúde, fortalecendo um sistema para os consumidores e deixando o SUS restrito apenas aos cidadãos pobres, por meio de programas precários e focalizados.

\section{Movimento social pela saúde e contexto neoliberal}

Como visto anteriormente, a construção do SUS é fruto da luta do movimento social, porém os anos seguintes indicam novos rumos dessa conquista. As agências internacionais promoveram uma série de mudanças que restringiu o papel do Estado e dificultou a consolidação legal do SUS 7 . Houve retrocesso nos canais de participação e desrespeito à sociedade civil por parte do Estado, que não formulou nenhuma estratégia para alimentar uma política descentralizada e participativa, conforme previsto nas diretrizes do sistema único de saúde.

Segundo Bravo e Menezes (2010), a política de saúde no Brasil sofre os impactos da política macroeconômica consolidada com o questionamento da universalidade e a implantação de políticas focalizadas e precárias ${ }^{8}$. Portanto, os desafios estão presentes para os que defendem o projeto da reforma sanitária e fazem parte do movimento social na saúde, que, durante os anos 1990, apresentou uma postura defensiva a fim de resistir às tentativas de mutilação dos princípios do SUS. Essa postura materializou-se em algumas conferências realizadas nos anos seguintes, as quais buscavam fortalecer o controle social. Em 2003, destacou-se a $12^{\mathrm{a}}$ Conferência Nacional de Saúde, com a temática "A saúde que temos e a saúde que queremos". Houve ainda, várias conferências temáticas relacionadas à saúde bucal, do trabalhador, educação em saúde e à saúde indígena.

Em 2005, foi realizado o $8^{\circ}$ Simpósio sobre a Política Nacional de Saúde, que, com a presença de mais de 800 participantes, formulou propostas de compromisso com os princípios da universalidade do acesso e a integralidade das ações em saúde. Em 2006, foi organizado o Encontro Nacional de Conjuntura e Saúde, cujo objetivo era fortalecer o projeto da reforma sanitária e reafirmar o debate para reconstrução de um novo campo político de estratégias e ações que articulassem as diversas lutas na saúde.

Apesar de todos esses espaços de debate, construídos com a finalidade de afirmar o compromisso com os princípios da reforma sanitária, a partir de 2007, surgem ideários contrários às propostas iniciadas nos meados dos anos de 1970. Assim, são criadas as Fundações Estatais de Direito Privado', instituídas pelo poder público e sem fins lucrativos, como proposições de enfrentamento dos mais preocupantes para os defensores do SUS.

Para compensar essas situações, foi realizada, ainda em 2007, a $13^{\text {a }}$ Conferência Nacional de Saúde, que apresentou como tema central "Saúde e Qualidade de Vida" e buscou alimentar estratégia de participação social no enfrentamento dos desafios postos pelo contexto atual, a fim de garantir a efetivação real do SUS.

A $13^{a}$ Conferência Nacional da Saúde marcou a rejeição da criação das Fundações Estatais do Direito Privado, apontou para o aprofundamento de políticas universalistas e o respeito à autonomia dos conselhos de saúde em relação ao governo. No entanto, o projeto da Fundação Estatal de Direito Privado mantém-se no Programa do governo conhecido como "Mais Saúde", criado em dezembro de 2007.

Com o objetivo de privatizar a saúde e neutralizar o controle social democrático, a proposta das Fundações Públicas de Direito Privado passa a ser defendida com mais rigor em 2009, no Congresso Nacional. 
Apresenta valores que desconfiguram o SUS e mutilam as conquistas adquiridas pela luta do movimento social da saúde, longamente construídas. Nesses termos, apresenta-se a proposta do grande capital de privatizar a previdência social e a saúde. A proposta para assistência social configura-se na focalização da pobreza, abrangendo a população que apresenta maior vulnerabilidade social ${ }^{10}$.

O projeto do grande capital aponta a saúde não como direito universal, mas como um serviço que pode ser comprado no âmbito do privado. A saúde torna-se mercadoria, vista como fonte de lucro e acumulação de capital. Nesse sentido, vivencia-se um processo de privatização do SUS com os chamados novos modelos de gestão ${ }^{11}$, que fortalecem a autonomia do mercado com abertura à iniciativa privada para os serviços de saúde. Isto é, vivencia-se a privatização da saúde pública no Brasil.

Nessa dinâmica de privatização do SUS, surge a Frente Nacional contra a Privatização da Saúde no Brasil, em maio de 2010. Fruto das articulações dos fóruns de saúde dos estados de Alagoas, Rio de Janeiro, Paraná e São Paulo, os quais buscavam procedência de ação direta contra a lei ${ }^{12}$ que sugere as Organizações Sociais na gestão da saúde pública. Esse movimento social apresenta como foco principal a luta em defesa da saúde pública, estatal e universal.

A Frente Nacional contra a Privatização do SUS objetiva romper com as bases do setor privado na saúde e fortalecer os princípios da reforma sanitária. Esse movimento social possibilita a construção de espaços democráticos a fim de resistir aos interesses do capital e, assim, enfrentar o processo de privatização da saúde. Marcou presença na $14^{\mathrm{a}}$ Conferência Nacional de Saúde, pois confrontou as propostas das novas formas de gestão que expressam o processo de desmonte do SUS. Nesse espaço, foi defendida a questão da ampliação do financiamento e dos recursos para a saúde e foi exigida a imediata regulamentação da emenda que aprova $10 \%$ da receita corrente bruta para a saúde e todos os seus níveis de atenção: básica, média e alta complexidade.

Os objetivos da Frente Nacional e dos fóruns materializam-se em desafios que surgem constantemente na luta pela defesa da saúde pública, estatal e de qualidade e revela a importância do controle democrático nesse processo de resistência contra as novas formas de gestão imposta pelo capital.

Nesses termos, efetiva-se a capacidade que o controle social possui para intervir na política de saúde, apresentando estratégias de fortalecimento das políticas de democratização do SUS e, consequentemente, de resistência à privatização da saúde. Além disso, faz-se necessário ressaltar que a participação da comunidade ${ }^{13}$ é uma das diretrizes apontadas no Sistema Único de Saúde e sua efetivação ocorre via Conselhos e Conferências.

No entanto, notifica-se que os mencionados mecanismos de participação foram implementados num cenário de globalização que amortece as lutas sociais e produz efeitos regressivos para a classe trabalhadora. É nesse contexto adverso à ampliação e efetivação dos direitos sociais que os mecanismos de controle democrático necessitam ganhar visibilidade a fim de criar estratégias de resistências à mercantilização da saúde pública, estatal e de qualidade.

Torna-se essencial, portanto, reconhecer que os fóruns de saúde e a Frente Nacional contra a Privatização inscrevem-se como novas formas de controle democrático, que agregam os movimentos sociais, com a finalidade de garantir o processo de construção e consolidação completa do SUS, impedindo os interesses do grande capital, o qual não mede esforços para mercantilizar a saúde pública.

\section{Considerações finais}

A redefinição do papel do Estado, via formação de um Estado mínimo, e a autonomia do mercado perante a sociedade capitalista indicam um cenário de globalização, de precarização e focalização das políticas sociais, de novos mecanismos de gestão do trabalho e também da fragilização dos espaços de participação democrática.

Essa nova dinâmica de acumulação do capital vem provocando a ampliação da miséria e a consolidação da cultura do consumo exagerado. Como apresenta Mota (1995), vivenciamos assim, a formação de dois tipos de cidadãos: o cidadão consumidor e o cidadão pobre.

Esse fato reitera a noção de política social específica para os pobres: a assistência social. A política de saúde junto à previdência social é direcionada ao cidadão consumidor, via processo de mercantilização. Constata-se, portanto, a concretização de uma cultura privatista da Seguridade Social brasileira.

O direito à saúde (como os outros direitos sociais) vem sofrendo, de alguma forma, ataques do capital, seja pela privatização, seja pela focalização e precarização dessas políticas. Mota (1995) assinala que o objetivo do capital é privatizar e assistencializar a Seguridade Social.

O contexto atual indica desafios para a real efetivação do SUS, pois permite assistir a disputa entre dois grandes projetos antagônicos na saúde. O privatista, que aposta na saúde como fonte de lucro e o da reforma sanitária, que apresenta a saúde como direito social de caráter universal e estatal. 
É nesta realidade de desmonte dos direitos sociais e, consequentemente, do SUS, que se torna necessário resgatar o protagonismo do movimento social pela saúde com a finalidade de superar as propostas impostas pelas agências internacionais do grande capital. Para tanto, torna-se relevante construir uma vontade coletiva de mobilização pela saúde, que busque democratizar a consciência sanitária (compreendida como interesse da comunidade e direito social) e que aposte na transformação da sociedade.

\section{Referências}

BRASIL. Presidência da República. Lei n. 8.080, de 19 de setembro de 1990a. Disponível em: <http://www.planalto.gov.br/ccivil_03/ leis/18080.htm>. Acesso em: 12 jan. 2013.

. Presidência da República. Lei n. 8.142, de 28 de dezembro de 1990b. Disponível em: <http://www.planalto.gov.br/ccivil_03/ leis/18142.htm>. Acesso em: 12 jan. 2013.

. Presidência da República. Lei n. 9.637, de 15 de maio de 1998. Disponível em: <http://www.planalto.gov.br/ccivil_03/leis/ 19637.htm>. Acesso em: 12 jan. 2013.

BRAVO, M. I. Saúde e Serviço Social. São Paulo: Cortez; Rio de Janeiro: UERJ, 2004.

. Serviço Social e reforma sanitária: lutas sociais e práticas profissionais. São Paulo: Cortez, 2007.

BRAVO, M. I.; MENEZES, J. S. B. de. Movimentos sociais, saúde e trabalho. Rio de Janeiro: ENSP/Fiocruz, 2010.

BRAZ, M. Mudanças no perfil das lutas de classes e modismos conceituais: o tormento de Sísifo das ciências sociais. In: BRAVO, M. I. S.; MENESES, J. B. (Org.). Saúde, Serviço Social, movimentos sociais e conselhos. São Paulo: Cortez, 2012, p. 220-247.

DOIMO, A. M. A vez e a voz popular: movimentos sociais e participação política no Brasil pós-1970. Rio de Janeiro: Anpocs, 1995. MOTA, A. E. Cultura da crise e Seguridade Social: um estudo sobre as tendências da previdência e da assistência social brasileira nos anos 1980 e 1990. São Paulo: Cortez, 1995.

NETTO, J. P. Transformações societárias e Serviço Social: notas para uma análise prospectiva da profissão no Brasil. Serviço Social \& Sociedade, ano XVII, n. 50, p. 87-132, abr. 1996.

REVISTA POLI. Saúde, Educação, Trabalho. Constituição cidadã completa 20 anos. Escola Politécnica de Saúde Joaquim Venâncio, ano 1 , n. 1, set/out, 2008. Disponível em: <http://www.epsjv.fiocruz.br/upload/EdicoesRevistaPoli/R1.pdf>. Acesso em: 12 jan. 2013.

SIMIONATTO, I. Caminhos e descaminhos da política de saúde no Brasil. Revista Inscrita, Brasília: CFESS, n. 1, p. 15-20, 1997. TEIXEIRA, M. J. de O. A Fundação Estatal de direito privado na saúde: um modelo de gestão democrático? In: BRAVO, M. I.; MENEZES, J. S. B. de (Org.). Saúde, Serviço Social, movimentos sociais e conselhos. São Paulo: Cortez, 2012, p 55-84, 2012.

\section{Notas}

1 O movimento sanitário nasce nos meados dos anos 1970 com o objetivo de pressionar o Estado para promover mudanças na política de saúde. Havia nesse período uma organização dos profissionais de saúde, como também, um número considerável de produção teórica vinculada à questão da saúde coletiva.

2 Esse movimento tinha como objetivo difundir a Teologia da Libertação que originou o Movimento contra o Custo de Vida. Este último conseguiu um número considerável de assinaturas da sociedade civil para o congelamento dos preços de gênero alimentícios por parte do Estado (BRAVO, 2007).

3 A década de 1980é considerada a "década perdida", pois a economia brasileira enfrenta um processo recessivo com a estagnação da economia, a expansão da inflação e a baixa capacidade produtiva das empresas. A esse respeito, ver Mota (1995).

4 Em abril de 1984, foi votada uma emenda que estabelecia eleições diretas para presidente no Brasil. Mesmo não alcançando maioria dos votos para sua aprovação esse movimento social de massa fortaleceu a sociedade civil e assumiu caráter exitoso na derrota da ditadura militar (BRAVO, 2007).

5 A categoria controle social é caracterizada pela participação da sociedade civil na elaboração e implantação das políticas de saúde e possui como instrumentos básicos os conselhos e conferências de saúde, que propiciam espaços para participação da população.

6 O projeto neoliberal aposta na cultural dos indivíduos e não da sociedade, pois na atual conjuntura, observa-se um rompimento dos fios que ligavam os humanos a uma textura social, a uma sociedade. Ver Netto (1996).

7 Éneste contexto neoliberal de formação do Estado mínimo do fortalecimento da autonomia do mercado que a lei n. 8.080-Lei Orgânica da Saúde -é promulgada (BRASIL, 1990a).

8 Durante o Governo Itamar Franco (1992-1994) houve o fim dos 30\% de recursos da Seguridade Social para saúde. Desta forma, a saúde, perdendo mais da metade de seus recursos, passou a ser vista como a "vilā" dos impasses financeiros do país. Ver Revista Poli (2008, p. 16).

9 Criadas através de Projeto de Lei Complementar n. 92/200, como novo modelo de gestão à administração pública. Sobre isso, ver Teixeira (2012).

10 A política neoliberal introduz o mercado como mecanismo de regulação no acesso dos trabalhadores à previdência e saúde. Esses direitos são metamorfoseados em mercadoria pelo grande capital.

11 Esses modelos desdobram-se em: Organizações Sociais (OS), Organização da Sociedade Civil de Interesse Público (Oscips), Fundações Estatais de Direito Privado (Fedps) e Empresa Brasileira de Serviços Hospitalares (Ebserh). 
12 Lein. 9.637/98 (BRASIL, 1998).

13 Lein. 8.142/90 (BRASIL, 1990b).

\section{Marta Alves Santos}

martaalves.s@oi.com.br

Professora do Curso de Serviço Social da Associação Brasileira de Ensino Universitário (ABEU)

Doutoranda em Política Social pela Universidade Federal Fluminense (UFF)

Orientadora: Profa. Dra. Mônica de Castro Maia Senna

\section{ABEU - Curso de Serviço Social}

Rua Itaiara, 301 - Centro

Belford Roxo - Rio de Janeiro - Brasil

CEP: 26113-400 